\title{
A parsimonious explanation for intersecting perinatal mortality curves: understanding the effects of race and of maternal smoking K S Joseph*1, Kitaw Demissie ${ }^{2}$, Robert W Platt ${ }^{3}$, Cande V Ananth ${ }^{4}$, Brian J McCarthy 5 and Michael S Kramer ${ }^{3}$
}

\begin{abstract}
Address: ${ }^{1}$ Perinatal Epidemiology Research Unit, Departments of Obstetrics and Gynaecology and of Pediatrics, Dalhousie University, Halifax Nova Scotia, Canada, ${ }^{2}$ Department of Environmental and Community Medicine, Robert Wood Johnson Medical School, University of Medicine and Dentistry of New Jersey, Piscataway, USA, ${ }^{3}$ Departments of Pediatrics and of Epidemiology and Biostatistics, McGill University, Montreal, Quebec, Canada, ${ }^{4}$ Section of Epidemiology and Biostatistics, Department of Obstetrics, Gynecology and Reproductive Sciences, Robert Wood Johnson Medical School, University of Medicine and Dentistry of New Jersey, Piscataway, USA and ${ }^{5}$ Centers for Disease Control and Prevention, Atlanta, Georgia, USA

Email: K S Joseph* - kjoseph@dal.ca; Kitaw Demissie - Demisski@umdnj.edu; Robert W Platt - robert.platt@mcgill.ca; Cande V Ananth - cande.ananth@umdnj.edu; Brian J McCarthy - bjm1@cdc.gov; Michael S Kramer - michael.kramer@mcgill.ca

* Corresponding author
\end{abstract}

Published: 16 April 2004

BMC Pregnancy and Childbirth 2004, 4:7
Received: 30 December 2003

Accepted: 16 April 2004

This article is available from: http://www.biomedcentral.com/I47/-2393/4/7

(C) 2004 Joseph et al; licensee BioMed Central Ltd. This is an Open Access article: verbatim copying and redistribution of this article are permitted in all media for any purpose, provided this notice is preserved along with the article's original URL.

\begin{abstract}
Background: Neonatal mortality rates among black infants are lower than neonatal mortality rates among white infants at birth weights $<3000 \mathrm{~g}$, whereas white infants have a survival advantage at higher birth weights. This finding is also observed when birth weight-specific neonatal mortality rates are compared between infants of smokers and non-smokers. We provide a parsimonious explanation for this paradoxical phenomenon.
\end{abstract}

Methods: We used data on births in the United States in 1997 after excluding those with a birth weight $<500 \mathrm{~g}$ or a gestational age $<22$ weeks. Birth weight- and gestational age-specific perinatal mortality rates were calculated per convention (using total live births at each birth weight/ gestational age as the denominator) and also using the fetuses at risk of death at each gestational age.

Results: Perinatal mortality rates (calculated per convention) were lower among blacks than whites at lower birth weights and at preterm gestational ages, while blacks had higher mortality rates at higher birth weights and later gestational ages. With the fetuses-at-risk approach, mortality curves did not intersect; blacks had higher mortality rates at all gestational ages. Increases in birth rates and (especially) growth-restriction rates presaged gestational age-dependent increases in perinatal mortality. Similar findings were obtained in comparisons of smokers versus nonsmokers.

Conclusions: Formulating perinatal risk based on the fetuses-at-risk approach solves the intersecting perinatal mortality curves paradox; blacks have higher perinatal mortality rates than whites and smokers have higher perinatal mortality rates than nonsmokers at all gestational ages and birth weights.

Introduction

At birth weights less than 3,000 g, neonatal mortality rates among infants of smokers are lower than the neonatal mortality rates among infants of nonsmokers. Neonatal 
mortality rates at higher birth weights and overall neonatal mortality rates favor the infants of nonsmokers, however [1]. The same phenomenon occurs when white infants are compared with black infants [1-3]. This paradox, first identified by Yerushalmy over 30 years ago [1], has intrigued perinatologists and epidemiologists for decades. In fact, the finding has been identified as a general phenomenon $[4,5]$ which emerges when birth weightspecific neonatal or perinatal mortality curves are compared across plurality, race, parity, infant sex, altitude and country [2-13].

Until recently, no explanation has coherently addressed the paradox presented by intersecting perinatal mortality curves. Sophisticated statistical approaches [2-13], which invoke concepts such as relative birth weight (i.e., birth weight expressed in terms of the population mean and standard deviation) and relative gestational age, have succeeded in resolving the paradox but fail to provide a compelling and biologically plausible explanation. More importantly, use of relative birth weight or relative gestational age, although ingenious, represents a non-parsimonious departure from conventional epidemiologic and medical research practice where relative values of (adult) weight and age are rarely used. The use of relative gestational age has been previously described as "more radical" than use of relative birth weight [5]. The relative birth weight formulation also fails to distinguish between birth weight differences due to differences in gestational duration and birth weight differences due to fetal growth $[14,15]$.

The paradox presented by intersecting perinatal mortality curves is important because it suggests a potential flaw in our understanding of perinatal issues. Also, the observation that low birth weight infants of women who smoke are at lower risk of neonatal death relative to low birth weigth infants of nonsmokers may lead to the conclusion that maternal smoking has a beneficial effect if the baby is small. We recently described an alternative formulation of perinatal risk $[16,17]$ which eliminates the crossover phenomenon in gestational age-specific perinatal mortality rates between singletons and twins and between births to nulliparous and parous women [16]. In this paper, we demonstrate that the same solution is applicable to contrasts involving maternal race and smoking status. We also provide additional insights that support our solution for the paradox presented by intersecting perinatal mortality curves.

\section{Methods}

We used data on all live births and stillbirths in the United States in 1997 (National Center for Health Statistics 1997 perinatal mortality data file for all states and the District of Columbia). Live births and infant death records were previously linked and missing or inconsistent information on gestational age was imputed or replaced in a small fraction of records by the National Center for Health Statistics (Hyattsville, Maryland). Gestational age was imputed from the month and year of the last menstrual period (LMP) when LMP day was missing [18]. LMPbased gestational age information was replaced by the clinical estimate when the former was inconsistent with birth weight or when there was no information on LMP [19].

We first compared birth weight and gestational age distributions and birth weight- and gestational age-specific mortality rates among whites and blacks. All analyses were restricted to singleton live births and stillbirths $\geq 22$ weeks gestational age and $\geq 500 \mathrm{~g}$ birth weight. Mortality indices of interest included stillbirth and early neonatal ( 0 to 6 days), perinatal (stillbirths plus early neonatal deaths), neonatal (0 to 27 days), post-neonatal (28 to 364 days) and infant ( 0 to 364 days) mortality rates. In order to demonstrate the paradox of intersecting mortality curves, we first calculated birth weight- and gestational age-specific stillbirth and perinatal mortality rates by using the number of total births (stillbirths and live births) at each birth weight or gestational age as the denominator (as per convention). Similarly, we calculated birth weight-and gestational age-specific early neonatal, neonatal, post-neonatal and infant mortality rates (as per convention) by using the number of live births at each birth weight or gestational age as the denominator.

We then used the number of fetuses at risk of stillbirth at each gestation in order to calculate the gestational agespecific rates of stillbirth. For instance, the stillbirth rate at 32 weeks gestation was computed by dividing the number of stillbirths at 32 completed weeks by the number of live births and stillbirths at 32 or more completed weeks of gestation (i.e., all ongoing pregnancies at 32 weeks were included in the denominator). This implies that fetuses who went on to deliver at 33,34, and 35 or more weeks gestation were at risk of stillbirth at 32 weeks. Similarly, we calculated gestational age-specific rates of perinatal, early neonatal and neonatal mortality using the fetuses-atrisk approach. Thus a fetus (unborn) at 32 weeks gestation was considered to be at risk of birth and at risk of neonatal death at that gestation. This formulation is justified on substantive grounds and best illustrated by considering a growth-restricted fetus at 32 weeks in a pregnancy complicated by severe preeclampsia [17]. The fetus in this situation is at increased risk of stillbirth, birth, neonatal death and even of physical/mental handicap later in life $[17,20]$. Deaths in a preceding time segment (e.g., stillbirths) were viewed as competing risks (non-independent) in analyses of death involving succeeding time segments e.g., neonatal death [21]. This represents a survival analysis 
perspective with subjects (fetuses) censored at birth. Death soon after birth or cerebral palsy is assigned to the point of birth since these outcomes have their origins in pregnancy complications $[17,20]$.

We also examined gestational age-specific patterns of birth ("birth rates") and fetal growth-restriction using the fetuses-at-risk approach [16,17]. Gestational age-specific birth rates were calculated by dividing the number of births (live births and stillbirths) at any gestation by the number of fetuses at risk of birth at that gestation. Growth-restricted fetuses were identified among live births using the sex-specific $10^{\text {th }}$ percentile cut-off from a fetal growth standard based on live births in the United States [22]. The rate of gestational age-specific growthrestriction was calculated by dividing the number of small-for-gestational age live births at any gestation (i.e., those $<10^{\text {th }}$ percentile of birth weight for gestational age) by the number of fetuses at risk for birth at that gestation.

All the above-mentioned analyses were repeated using maternal smoking status as the determinant across which mortality curves intersect. For these analyses, we excluded all live births and stillbirths with a birth weight $<500 \mathrm{~g}$ or a gestational age $<22$ weeks and all multiple gestation births. We also excluded all live births and stillbirths that occurred in California, Indiana, New York and South Dakota, since these states did not provide information on smoking status [23].

\section{Results}

The rates of preterm birth ( $<37$ weeks) and low birth weight $(<2,500 \mathrm{~g})$ among whites were $8.8 \%$ and $5.0 \%$, respectively, while the corresponding rates among blacks were $15.8 \%$ and $11.1 \%$. This was a consequence of a 'shift to the left' in the gestational age and birth weight distributions of blacks relative to whites (Figure 1). The perinatal mortality rate was 6.1 per 1,000 total births among whites and 11.5 per 1,000 total births among blacks. Among whites, $65.9 \%$ of perinatal deaths occurred at preterm gestation and $67.0 \%$ occurred among those born low birth weight, while the corresponding figures for blacks were $76.0 \%$ and $77.4 \%$, respectively. Birth weight-specific neonatal mortality rates (per 1,000 live births at each birth weight) intersected, with blacks having lower neonatal death rates at birth weights $<3,000 \mathrm{~g}$ and higher neonatal mortality rates in birth weight categories $\geq 3,000 \mathrm{~g}$ (Figure 1).

Gestational age-specific neonatal mortality rates also intersected, with blacks having lower rates of neonatal mortality relative to whites at preterm gestational ages and higher rates at gestational ages $\geq 38$ weeks (Figure 2). Although gestational age-specific mortality curves of blacks and whites also intersected when stillbirth rates and early neonatal mortality rates were contrasted, there was no crossover in post-neonatal mortality rates (Figure 2).

When gestational age-specific mortality contrasts were recalculated using the fetuses-at-risk approach, the stillbirth, early neonatal, perinatal, neonatal, post-neonatal and infant mortality curves did not intersect (Figure 3 ). Mortality rates computed using the fetuses-at-risk approach showed that mortality rates increased with advancing gestational age (as opposed to the decline seen with the conventional formulation). Among whites, perinatal mortality rates increased from 0.21 per 1,000 at 32 weeks gestation, to 0.39 per 1,000 at 37 weeks and to 0.76 per 1,000 fetuses-at-risk at 40 weeks gestation (Table 1 ), whereas among blacks perinatal mortality rates increased from 0.47 per 1,000 at 32 weeks gestation, to 0.64 per 1,000 at 37 weeks and to 1.09 per 1,000 fetuses-at-risk at 40 weeks gestation (Table 2). Curves of race- and birth weight-specific perinatal and neonatal mortality also did not intersect when mortality rates were calculated using births at a given or higher birth weight as the denominator (not shown).

Birth rates among blacks were higher than birth rates among whites and gestational age-specific patterns of birth corresponded to gestational age-specific patterns of perinatal mortality upto 39 weeks gestation (Figure 4). Differences in birth rates between blacks and whites were evident at early gestational ages between 22 and 27 weeks as well (not shown). Fetal growth-restriction rates among whites and blacks also presaged rising rates of perinatal death. Patterns of fetal growth-restriction were congruent with perinatal mortality rates among whites and blacks at both preterm (28-36 weeks, Figure 4) and term gestational ages (37-42 weeks, Figure 4).

Analyses by maternal smoking status yielded essentially similar results (Figure 5); use of the fetuses-at-risk approach abolished the mortality crossover and showed higher mortality rates among smokers than among nonsmokers at all gestational ages (Tables 3 and 4). Birth rates among smokers were higher than birth rates among nonsmokers and corresponded to gestational age-specific patterns of perinatal death up to 37 weeks gestation. Birth rate differences at gestational ages 28 to 36 weeks were less pronounced than for the white-black contrast, however. Gestational age-specific growth restriction rates among smokers (fetuses-at-risk approach) were approximately 1.5 times higher than among nonsmokers at 32-33 weeks gestation (Tables 3 and 4). At 34 weeks gestation and beyond, growth-restriction rates among smokers were approximately two fold higher than among non-smokers. Growth-restriction rates among smokers and nonsmokers 

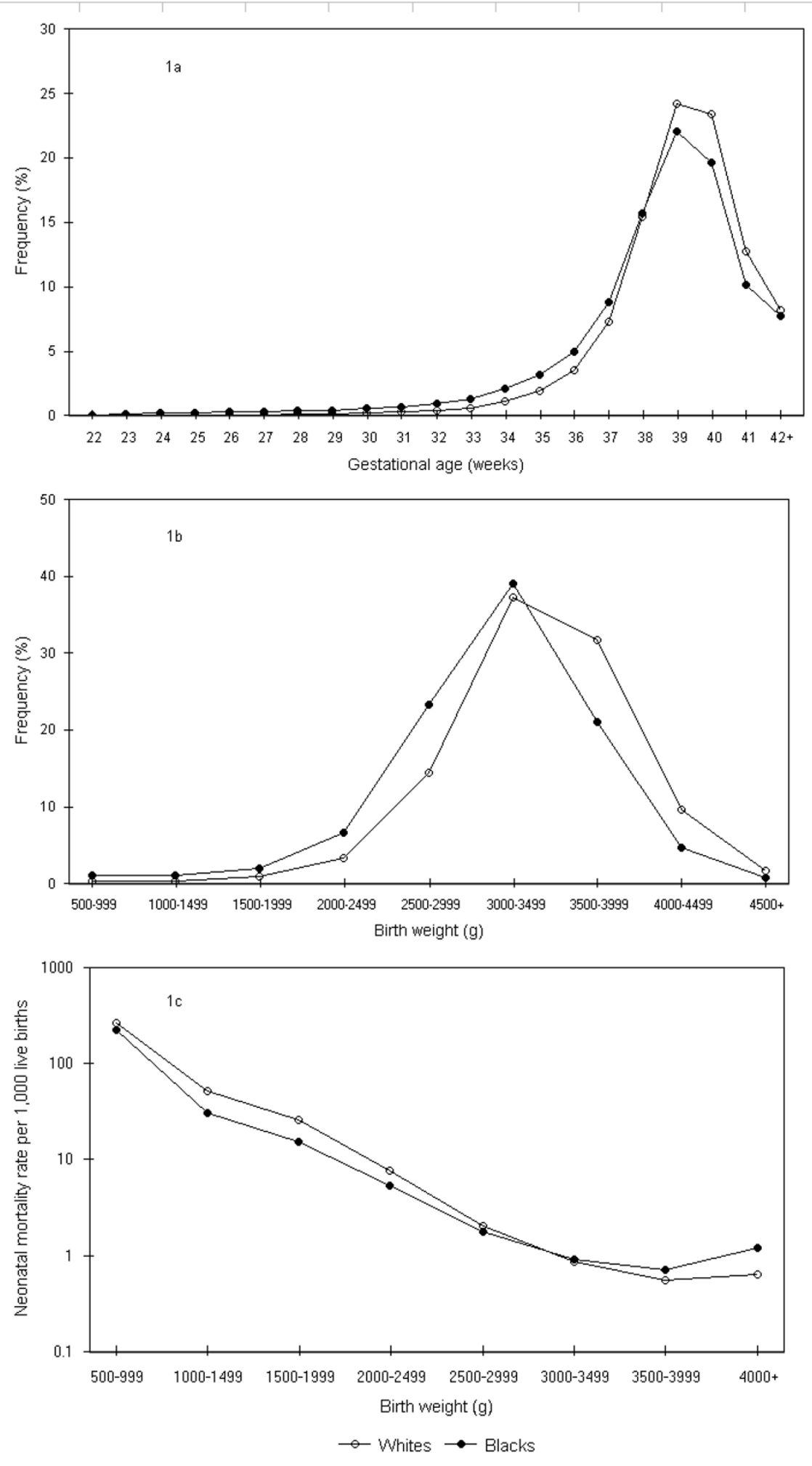

Figure I

Gestational age and birth weight distributions and birth weight-specific neonatal mortality rates among whites and blacks. Legend text: Gestational age ( $\mathrm{I}$ a) and birth weight (Ib) distributions and birth weight-specific neonatal mortality rates (Ic) among white and black births, United States, 1997. 

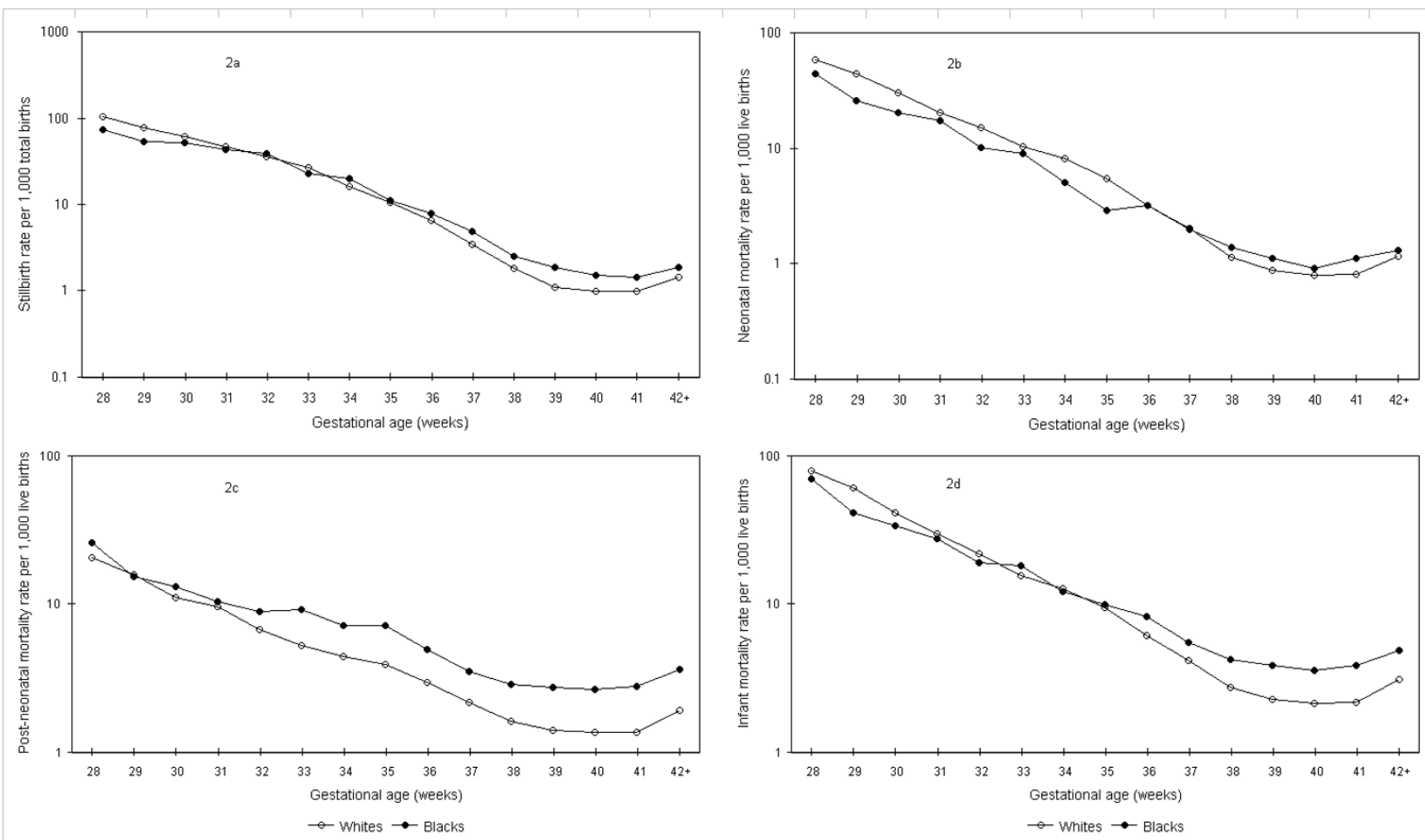

Figure 2

Gestational age-specific stillbirth, neonatal, post-neonatal and infant mortality rates among whites and blacks calculated as per convention. Legend text: Gestational age-specific stillbirth (2a), neonatal (2b), post-neonatal (2c), and infant (2d) mortality rates among white and black births calculated as per convention, United States, 1997.

increased with increasing gestation in parallel with rising perinatal mortality rates (Figure 5).

\section{Discussion}

Birth weight- and gestational age-specific fetal, perinatal, neonatal and infant mortality rates among whites and blacks and among nonsmokers and smokers intersect if these indices are calculated based on births that occur at any particular birth weight or gestational age. On the other hand, appropriate epidemiologic conceptualization of the candidates at risk of fetal, perinatal and neonatal death leads to the fetuses-at-risk approach and eliminates the crossover paradox. This represents a parsimonious solution to a paradox that has plagued the perinatal literature for over 3 decades.

The problem of intersecting birth weight-specific neonatal mortality curves as originally formulated by Yerushalmy [1] has several obfuscating elements. The first step towards a solution involves a shift from birth weight-specific mortality to gestational age-specific mortality (Figure
2). Such a shift in focus has been advocated in other contexts as well, since birth weight reflects the combined effects of gestational duration and fetal growth [24-26]. Recognizing that the crossover phenomenon is linked to pregnancy-related events flows from the demonstration that stillbirth and early neonatal, perinatal and neonatal mortality curves all show the crossover paradox, while post-neonatal mortality curves do not (Figure 2). The penultimate step in the solution involves reformulating the denominators necessary for calculating gestational age-specific stillbirth rates - this step eliminates the stillbirth crossover phenomenon. In fact, this reformulation of denominators for gestational age-specific stillbirth rates was first proposed over 15 years ago $[27,28]$ and is widely accepted $[16,17,29-38]$. The last and perhaps least obvious step in the solution involves a similar reformulation of the denominator for calculating gestational age-specific neonatal mortality rates. Accepting that fetuses-at-risk constitute the appropriate denominator for gestational age-specific perinatal and neonatal mortality rates is challenging. However, there are cogent substantive grounds 

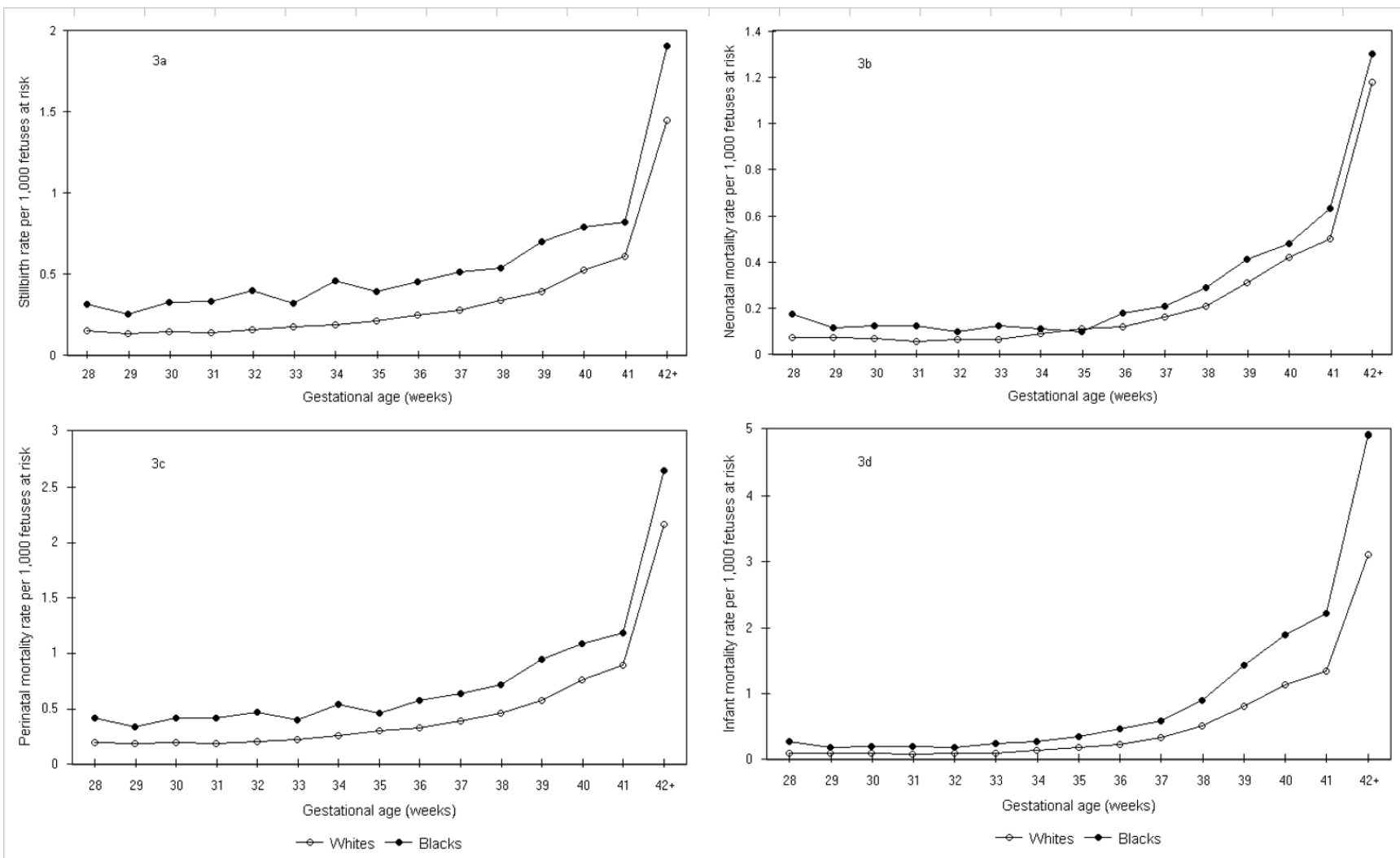

\section{Figure 3}

Gestational age-specific stillbirth, neonatal, perinatal, and infant mortality rates among whites and blacks calculated using the fetuses-at-risk approach. Legend text: Gestational age-specific stillbirth (3a), neonatal (3b), perinatal (3c), and infant (3d) mortality rates among white and black births calculated using the fetuses-at-risk approach, United States, 1997.

for accepting that fetuses at any gestation are at risk of birth and at risk of neonatal death $[16,17,29]$ and even cerebral palsy at that gestation $[17,20]$.

The use of the fetuses-at-risk approach eliminates the perinatal mortality crossover and shows that blacks have higher gestational age-specific mortality rates than whites at all gestational ages. Similarly, gestational age-specific perinatal mortality rates are higher among smokers than among non-smokers at all gestational ages. Presumably, a relatively unfavorable intrauterine environment among blacks is responsible for both a higher birth rate at preterm gestation and a higher rate of intrauterine growthrestriction. Among smokers, the adverse uterine environment appears to have a larger effect on the pattern of growth-restriction than on the pattern of birth (Figure 5). Rates of birth, intrauterine growth-restriction and mortality all increase with increasing gestational age and differentially alter the ratio of deaths to survivors (among white and black births and among births to smokers and non- smokers) and this leads to the paradox of intersecting perinatal mortality curves (under the traditional persective). The relationship between the higher rates of birth and growth-restriction (which are both associated with a unfavorable uterine environment) is a matter of speculation. The dissonance between birth rates and growthrestriction rates at term gestation (note cross over in birth rates but not growth-restriction rates, Figures 4 and 5), suggest that birth rates and growth-restriction rates may be independently affected by an the uterine environment. Some of the differences in birth rates at preterm and especially at term gestation and also in growth-restriction rates may be due to the differential use of labour induction and/or cesarean delivery in the contrasted populations, however [23].

The adoption of the fetuses-at-risk approach has important clinical and epidemiologic implications. The risk of stillbirth increases with advancing gestational age. From the perspective of fetuses, those with a longer gestational 

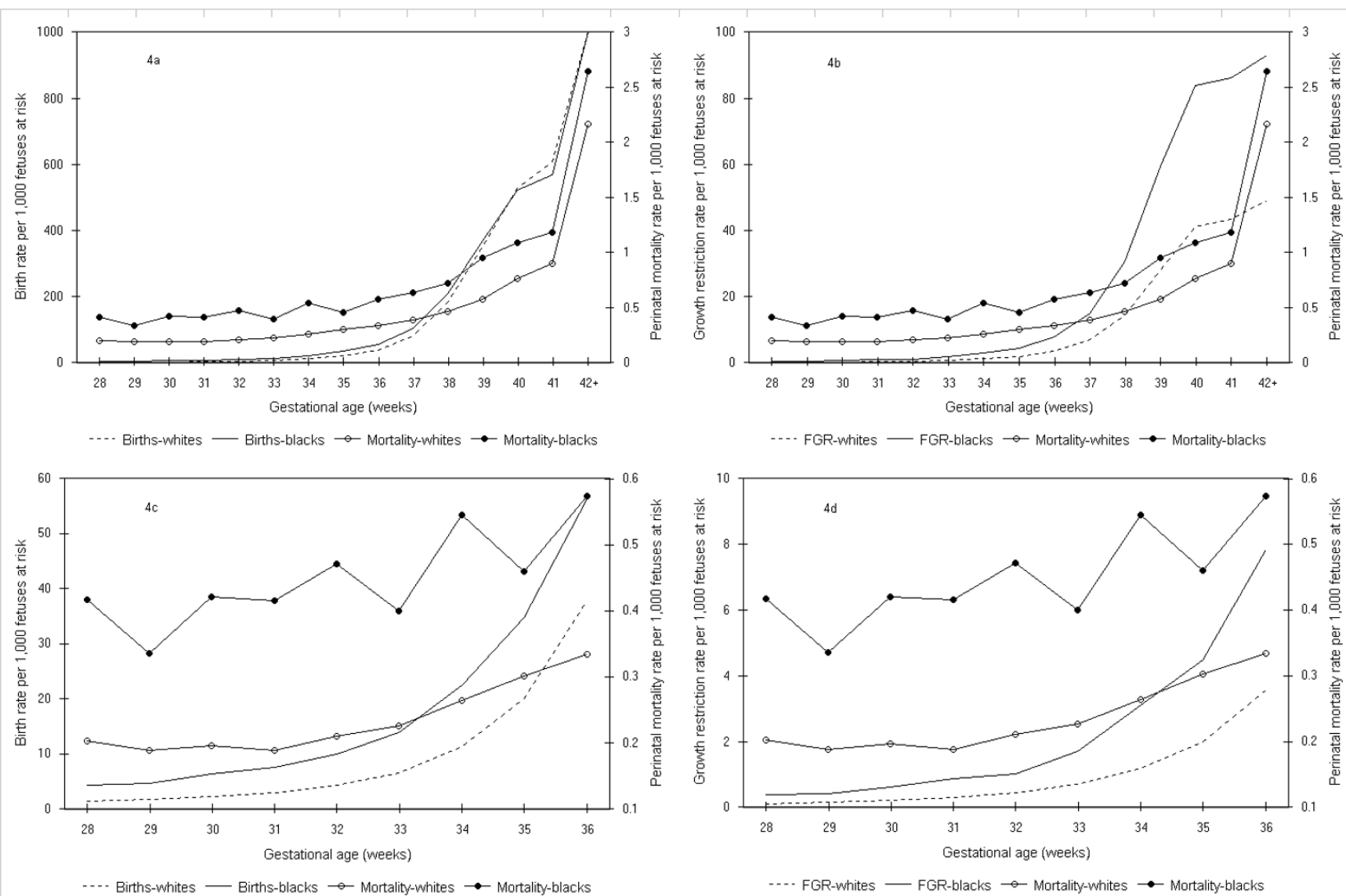

Figure 4

Birth rates, fetal growth-restriction rates (FGR) and perinatal mortality rates among whites and blacks. Legend text: Birth rates $(4 a$ and $4 c)$ and fetal growth-restriction (FGR) rates ( $4 b$ and $4 d)$ in relation to perinatal mortality rates at 28 to $\geq 42$ weeks (4a and $4 b$ ) and at 28 to 36 weeks gestation (4c and $4 d$ ) among white and black births calculated using the fetuses-at-risk approach, United States, 1997.

duration also suffer higher rates of neonatal mortality. These findings provide a preliminary theoretical justification for recent population increases in medically-indicated labour induction at preterm, term and post-term gestation [39-41] and represent an instance of obstetric theory catching up with obstetric practice. Recent increases in labour induction cannot be reconciled with conventionally calculated patterns of gestational age-specific stillbirth and neonatal mortality (both of which decrease with increasing gestation). On the other hand, selective and carefully timed early delivery in high-risk pregnancy is consistent with rising rates of gestational agespecific perinatal mortality observed under the fetuses-atrisk approach. It is noteworthy that although a few advances in obstetrics have permitted the prolongation of gestational duration in some high-risk pregnancies (e.g., through intrauterine blood transfusions in Rh hemolytic disease of the newborn), such maneuvers have only had a modest effect in preventing stillbirth and neonatal death. Temporal reductions in perinatal mortality owe more to early delivery (including delivery at preterm gestation) achieved through labour induction and/or cesarean delivery and supportive advances in neonatal care (than to prolongation of pregnancy). On the other hand, our findings do not support early delivery that is not medically indicated. The risk of perinatal death and/or serious neonatal morbidity in a normal pregnancy (and even on average, see Figure 3 ) is small and the increase in such risk per gestational week is small as well. Early delivery can be justified only in carefully selected cases of high-risk pregnancy where signs of fetal compromise indicate a high and sharply rising absolute risk of perinatal mortality and/or serious neonatal morbidity [17]. 

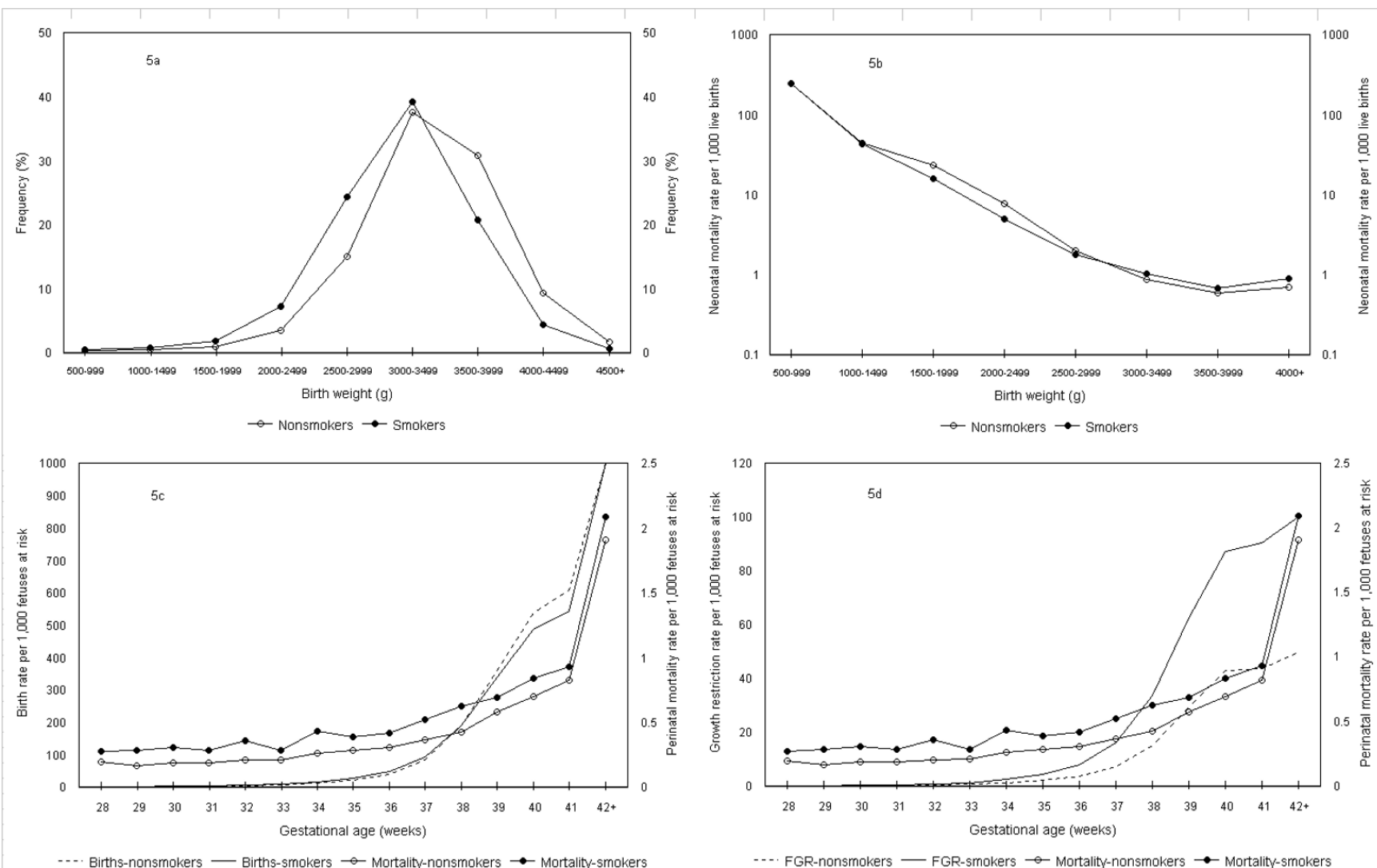

Figure 5

Birth weight distributions, birth weight-specific neonatal mortality rates, birth rates, fetal growth-restriction (FGR) rates and perinatal mortality rates among smokers and nonsmokers. Legend text: Birth weight distributions (5a), birth weight-specific neonatal mortality rates $(5 b)$, birth rates in relation to perinatal mortality rates $(5 c)$ and fetal growth-restriction (FGR) rates in relation to perinatal mortality rates (5d) among births to smokers and nonsmokers calculated using the fetuses-at-risk approach, United States, 1997.

Other clinical implications of our study relate to the assumptions underlying the creation of fetal growth standards. For example, the use of a fixed percentile cutoff for identifying small-for-gestational implies a constant rate of growth-restriction across gestation (e.g., approximately $10 \%$ of live births at each gestation will be smallfor-gestational age if the $10^{\text {th }}$ percentile cut-off is used), whereas our formulation shows that gestational age-specific growth-restriction rates increase with increasing gestation (Tables 3 and 4). Our formulation of rising gestational age-specific growth-restriction rates is congruent with our finding that gestational age-specific perinatal mortality rates rise with increasing gestational age (Figures 4 and 5). The fetuses-at-risk approach also provides a methodology for empirically determining the need for customized fetal growth standards [42].
Our conceptualization of gestational age-specific risks also has major implications for epidemiologic research. Logistic models of perinatal death which adjust for gestational age or birth weight implicitly use the conventional denominators and provide an average of the opposing gestational age- or birth weight-specific effects of race and maternal smoking on mortality. In fact, gestational age and birth weight are better viewed as variables in the causal pathway between fetal compromise and death. Another caveat stems from the pattern of gestational agedependent increases in mortality rates in contrasted populations - as observed in this study and elsewhere $[16,34,43]$ these rates are not proportional across gestational age. Finally, it should be recognized that the time scales used for events that occur in utero (viz., gestational age) and events that occur in infancy (viz., age) overlap because they have different anchors (last menstrual period and birth, respectively). The problems that 
Table I: Numbers and Rates of Live Births, Stillbirths and Neonatal Deaths among Singletons Births, Whites, United States, 1997.

\begin{tabular}{|c|c|c|c|c|c|c|c|c|c|c|}
\hline $\begin{array}{l}\text { Gestational } \\
\text { age }\end{array}$ & Stillbirths & Live births & $\begin{array}{c}\text { Neonatal } \\
\text { deaths }\end{array}$ & $\begin{array}{l}\text { Stillbirth rate } \\
(\mathrm{I})^{*}\end{array}$ & $\begin{array}{l}\text { Perinatal } \\
\text { mortality rate } \\
(\mathrm{I})^{*}\end{array}$ & $\begin{array}{l}\text { Neonatal } \\
\text { mortality rate } \\
(I)^{*}\end{array}$ & $\begin{array}{l}\text { Fetuses-at- } \\
\text { risk }\end{array}$ & $\begin{array}{l}\text { Stillbirth rate } \\
(2)^{*}\end{array}$ & $\begin{array}{l}\text { Perinatal } \\
\text { mortality rate } \\
(2)^{*}\end{array}$ & $\begin{array}{l}\text { Neonatal } \\
\text { mortality rate } \\
(2)^{*}\end{array}$ \\
\hline 32 & 464 & 12,378 & 188 & 36.1 & 48.0 & 15.2 & $2,932,342$ & 0.16 & 0.21 & 0.06 \\
\hline 33 & 515 & 18,462 & 193 & 27.1 & 34.8 & 10.5 & $2,919,500$ & 0.18 & 0.23 & 0.07 \\
\hline 34 & 549 & 32,600 & 269 & 16.6 & 23.1 & 8.3 & $2,900,523$ & 0.19 & 0.26 & 0.09 \\
\hline 35 & 621 & 56,901 & 317 & 10.8 & 15.1 & 5.6 & $2,867,374$ & 0.22 & 0.30 & 0.11 \\
\hline 36 & 695 & 105,595 & 340 & 6.5 & 8.8 & 3.2 & $2,809,852$ & 0.25 & 0.33 & 0.12 \\
\hline 37 & 750 & 215,174 & 437 & 3.5 & 4.9 & 2.0 & $2,703,562$ & 0.28 & 0.39 & 0.16 \\
\hline 38 & 847 & 457,012 & 520 & 1.8 & 2.5 & I.I & $2,487,638$ & 0.34 & 0.46 & 0.21 \\
\hline 39 & 796 & 715,694 & 628 & 1.1 & 1.6 & 0.9 & $2,029,779$ & 0.39 & 0.58 & 0.31 \\
\hline 40 & 690 & 691,945 & 551 & 1.0 & 1.4 & 0.8 & $1,313,289$ & 0.53 & 0.76 & 0.42 \\
\hline 41 & 379 & 377,523 & 311 & 1.0 & 1.5 & 0.8 & 620,654 & 0.61 & 0.90 & 0.50 \\
\hline$\geq 42 \dagger$ & 351 & $242,40 \mathrm{I}$ & 286 & 1.4 & 2.2 & 1.2 & 242,752 & 1.45 & 2.16 & 1.18 \\
\hline Total $\ddagger$ & 12,987 & $2,986,954$ & 7,520 & 4.3 & 6.1 & 2.5 & $2,999,941$ & 4.33 & 6.12 & 2.51 \\
\hline
\end{tabular}

* Total births at each gestational week served as the denominator for stillbirth and perinatal mortality rates (I), while live births at each gestational week constituted the denominator for neonatal mortality rates (I). Stillbirth, perinatal (stillbirths plus early neonatal deaths) and neonatal mortality rates (2) were calculated using fetuses-at-risk as the denominator (see text). All rates are expressed per I,000. $\dagger$ This period of risk exceeds I week and partly explains the large increase in the perinatal mortality (2). $¥$ All gestational ages, including those $<32$ weeks and those with missing gestational age.

Table 2: Numbers and Rates of Live Births, Stillbirths and Neonatal Deaths among Singletons Births, Blacks, United States, 1997.

\begin{tabular}{|c|c|c|c|c|c|c|c|c|c|c|}
\hline $\begin{array}{l}\text { Gestational } \\
\text { age }\end{array}$ & Stillbirths & Live births & $\begin{array}{c}\text { Neonatal } \\
\text { deaths }\end{array}$ & $\begin{array}{l}\text { Stillbirth rate } \\
(I)^{*}\end{array}$ & $\begin{array}{l}\text { Perinatal } \\
\text { mortality rate } \\
(1)^{*}\end{array}$ & $\begin{array}{l}\text { Neonatal } \\
\text { mortality rate } \\
(1)^{*}\end{array}$ & $\begin{array}{l}\text { Fetuses-at- } \\
\text { risk }\end{array}$ & $\begin{array}{l}\text { Stillbirth rate } \\
(2)^{*}\end{array}$ & $\begin{array}{l}\text { Perinatal } \\
\text { mortality rate } \\
(2)^{*}\end{array}$ & $\begin{array}{l}\text { Neonatal } \\
\text { mortality rate } \\
(2)^{*}\end{array}$ \\
\hline 32 & 222 & 5,354 & 55 & 39.8 & 47.2 & 10.3 & 558,038 & 0.40 & 0.47 & 0.10 \\
\hline 33 & 179 & 7,552 & 69 & 23.2 & 28.6 & 9.1 & 552,462 & 0.32 & 0.40 & 0.12 \\
\hline 34 & 251 & 11,994 & 61 & 20.5 & 24.3 & 5.1 & 544,731 & 0.46 & 0.55 & 0.11 \\
\hline 35 & 211 & 18,277 & 53 & 11.4 & 13.3 & 2.9 & 532,486 & 0.40 & 0.46 & 0.10 \\
\hline 36 & 233 & 28,729 & 93 & 8.0 & 10.2 & 3.2 & 513,998 & 0.45 & 0.57 & 0.18 \\
\hline 37 & 251 & 50,631 & 101 & 4.9 & 6.1 & 2.0 & 485,036 & 0.52 & 0.64 & 0.21 \\
\hline 38 & 233 & 90,553 & 126 & 2.6 & 3.4 & 1.4 & 434,154 & 0.54 & 0.72 & 0.29 \\
\hline 39 & 241 & 126,796 & 142 & 1.9 & 2.6 & 1.1 & 343,368 & 0.70 & 0.95 & 0.41 \\
\hline 40 & 172 & $|13,15|$ & 104 & 1.5 & 2.1 & 0.9 & 216,331 & 0.80 & 1.09 & 0.48 \\
\hline 41 & 85 & 58,386 & 65 & 1.5 & 2.1 & 1.1 & 103,008 & 0.83 & 1.18 & 0.63 \\
\hline$\geq 42 \dagger$ & 85 & 44,452 & 58 & 1.9 & 2.6 & 1.3 & 44,537 & 1.91 & 2.65 & 1.30 \\
\hline Total $\ddagger$ & 4,760 & 579,956 & 2,725 & 8.1 & 11.5 & 4.7 & 584,716 & 8.14 & 11.5 & 4.66 \\
\hline
\end{tabular}

* Total births at each gestational week served as the denominator for stillbirth and perinatal mortality rates (I), while live births at each gestational week constituted the denominator for neonatal mortality rates (I). Stillbirth, perinatal (stillbirths plus early neonatal deaths) and neonatal mortality rates (2) were calculated using fetuses-at-risk as the denominator (see text). All rates are expressed per 1,000 . $\dagger$ This period of risk exceeds I week and partly explains the large increase in the perinatal mortality (2). $¥$ All gestational ages, including those $<32$ weeks and those with missing gestational age.

arise from the use of two overlapping time scales are well recognized [44] and can be avoided using a single time scale such as post-menstrual or post-conceptional age $[16,17,43]$.

The limitations of our study include those that attend the use of data from large databases. The estimates of gestational age are likely to be erroneous in a fraction of records. This is especially true for stillbirths; the gestational age at delivery of a stillbirth systematically overestimates the gestational age at death. However, this difference is not likely to be large in most instances, especially in recent years [27]. More importantly, this problem is unlikely to have affected our study results, since the crossover paradox was evident despite this limitation. Errors in the gestational age of live births may have influenced the gestational age-dependent mortality patterns to a small extent, although sensitivity analyses carried out after excluding births with imputed gestational ages showed similar patterns (data not shown). Other potential errors include under-reporting of smoking status [45], inconsistencies in data transcription and missing 
Table 3: Gestational Age-Specific Birth, Growth-Restriction and Perinatal Mortality Rates, Nonsmokers, United States, 1997.

\begin{tabular}{|c|c|c|c|c|c|c|c|c|c|c|}
\hline $\begin{array}{l}\text { Gestational } \\
\text { age }\end{array}$ & Live births & $\begin{array}{l}\text { SGA live } \\
\text { births }\end{array}$ & Stillbirths & $\begin{array}{c}\text { Neonatal } \\
\text { deaths }\end{array}$ & Fetuses at risk & Birth rate & $\begin{array}{l}\text { Growth- } \\
\text { restriction rate } \\
(\mathrm{I})^{*}\end{array}$ & $\begin{array}{l}\text { Growth- } \\
\text { restriction rate } \\
(2)^{*}\end{array}$ & $\begin{array}{l}\text { Perinatal } \\
\text { mortality rate } \\
(\mathrm{I})^{*}\end{array}$ & $\begin{array}{l}\text { Perinatal } \\
\text { mortality rate } \\
(2)^{*}\end{array}$ \\
\hline 32 & 11,972 & $|, 23|$ & 381 & 161 & $2,454,357$ & 5.0 & 10.3 & 0.5 & 41.3 & 0.21 \\
\hline 33 & 17,679 & 2,014 & 389 & 179 & $2,442,004$ & 7.4 & 11.4 & 0.8 & 29.0 & 0.21 \\
\hline 34 & 30,271 & 3,304 & 465 & 219 & $2,423,936$ & 12.7 & 10.9 & 1.4 & 21.0 & 0.27 \\
\hline 35 & 51,988 & 5,143 & 495 & 239 & $2,393,200$ & 21.9 & 9.9 & 2.2 & 12.9 & 0.28 \\
\hline 36 & 94,656 & 8,913 & 533 & 278 & $2,340,717$ & 40.7 & 9.4 & 3.9 & 7.6 & 0.31 \\
\hline 37 & 188,867 & 16,313 & 569 & 368 & $2,245,528$ & 84.4 & 8.6 & 7.4 & 4.4 & 0.37 \\
\hline 38 & 392,302 & 30,727 & 599 & 458 & $2,056,092$ & 191.1 & 7.8 & 15.1 & 2.2 & 0.43 \\
\hline 39 & $601,40 \mathrm{I}$ & 48,429 & 624 & 553 & $1,663,191$ & 362.0 & 8.1 & 29.6 & 1.6 & 0.58 \\
\hline 40 & 569,467 & 44,473 & 482 & 460 & $1,061,166$ & 537.1 & 7.8 & 42.9 & 1.3 & 0.70 \\
\hline 41 & 299,521 & 20,433 & 261 & 255 & 491,217 & 610.3 & 6.8 & 43.8 & 1.4 & 0.82 \\
\hline$\geq 42 \dagger$ & 191,199 & 8,325 & 236 & 216 & 191,435 & $1,000.0$ & 8.6 & 49.7 & 1.9 & 1.91 \\
\hline Total $\ddagger$ & $2,491,884$ & 198,876 & 8,976 & 6,878 & $2,500,860$ & $1,000.0$ & 8.1 & 80.9 & 5.6 & 5.55 \\
\hline
\end{tabular}

* Total births and live births at each gestational week served as the denominators for perinatal mortality rates (I) and growth-restriction rates (I), respectively. Perinatal mortality and growth-restriction rates (2) were calculated using the number of fetuses at risk as the denominator (see text). Fetuses-at-risk for the growth-restriction rate calculation exclude those over 44 weeks and those with missing gestational age or birth weight. All rates are expressed per I,000 except for growth-restriction rates (I) which are per 100 . $\dagger$ This period of risk exceeds I week and partly explains the large increase in the perinatal mortality rate (2). $¥$ All gestational ages, including those $<32$ weeks and those with missing gestational age. SGA denotes small for gestational age.

Table 4: Gestational Age-Specific Birth, Growth-Restriction and Perinatal Mortality Rates, Smokers, United States, 1997.

\begin{tabular}{|c|c|c|c|c|c|c|c|c|c|c|}
\hline $\begin{array}{l}\text { Gestational } \\
\text { age }\end{array}$ & Live births & $\begin{array}{c}\text { SGA live } \\
\text { births }\end{array}$ & Stillbirths & $\begin{array}{c}\text { Neonatal } \\
\text { deaths }\end{array}$ & Fetuses at risk & Birth rate & $\begin{array}{l}\text { Growth- } \\
\text { restriction rate } \\
\text { (I)* }\end{array}$ & $\begin{array}{l}\text { Growth- } \\
\text { restriction rate } \\
(2)^{*}\end{array}$ & $\begin{array}{l}\text { Perinatal } \\
\text { mortality rate } \\
(1)^{*}\end{array}$ & $\begin{array}{l}\text { Perinatal } \\
\text { mortality rate } \\
(2)^{*}\end{array}$ \\
\hline 32 & 2,562 & 279 & 103 & 38 & 369,256 & 7.3 & 10.9 & 0.8 & 48.3 & 0.36 \\
\hline 33 & 3,599 & 447 & 90 & 25 & 366,525 & 10.1 & 12.5 & 1.3 & 27.7 & 0.28 \\
\hline 34 & 6,086 & 893 & 119 & 45 & 362,764 & 17.2 & 14.7 & 2.5 & 24.9 & 0.43 \\
\hline 35 & 9,666 & $|, 49|$ & 102 & 56 & 356,447 & 27.6 & 15.5 & 4.3 & 14.1 & 0.39 \\
\hline 36 & 16,700 & 2,697 & 101 & 63 & 346,545 & 48.7 & 16.2 & 8.0 & 8.6 & 0.42 \\
\hline 37 & 30,540 & 5,267 & 126 & 77 & 329,572 & 93.5 & 17.3 & 16.4 & 5.6 & 0.52 \\
\hline 38 & 56,458 & 9,771 & 139 & 94 & $298,67 \mid$ & 190.4 & 17.3 & 33.6 & 3.3 & 0.63 \\
\hline 39 & 81,672 & 14,690 & 129 & 80 & 241,759 & 339.9 & 18.0 & 62.6 & 2.0 & 0.69 \\
\hline 40 & 77,426 & 13,368 & 101 & 67 & 159,576 & 488.1 & 17.3 & 87.3 & 1.7 & 0.84 \\
\hline 41 & 44,179 & 6,863 & 52 & 46 & 81,712 & 544.0 & 15.6 & 90.6 & 1.7 & 0.93 \\
\hline$\geq 42 \dagger$ & 37,017 & 3,161 & 53 & 49 & 37,289 & $1,000.0$ & 18.4 & 100.1 & 2.1 & 2.09 \\
\hline Total $\ddagger$ & 374,605 & 62,319 & 1,810 & 1,332 & $376,4 \mid 5$ & $1,000.0$ & 17.0 & 169.6 & 7.3 & 7.28 \\
\hline
\end{tabular}

* Total births and live births at each gestational week served as the denominators for perinatal mortality rates (I) and growth-restriction rates (I), respectively. Perinatal mortality and growth-restriction rates (2) were calculated using the number of fetuses at risk as the denominator (see text). Fetuses-at-risk for the growth-restriction rate calculation exclude those over 44 weeks and those with missing gestational age or birth weight. All rates are expressed per I,000 except for growth-restriction rates (I) which are per 100. † This period of risk exceeds I week and partly explains the large increase in the perinatal mortality rate (2). $¥$ All gestational ages, including those $<32$ weeks and those with missing gestational age. SGA denotes small for gestational age.

gestational age or birth weight information in a fraction of births ( $<1 \%$ among black and white live births). Finally, our estimates of fetal growth-restriction represent approximations [17], especially because they are based on growth-restricted live births at each gestation (i.e., "revealed" growth- restriction).

\section{Conclusions}

We have provided a parsimonious solution to the paradox of intersecting perinatal mortality curves among whites and blacks and among smokers and nonsmokers. Blacks have higher perinatal mortality rates than whites and smokers have higher perinatal mortality rates than nonsmokers at all gestational ages and birth weights. More importantly, the new perspective that emerges from the fetuses-at-risk formulation provides several important 
clinical and epidemiologic insights into perinatal health issues.

\section{Competing interests \\ None declared.}

\section{Authors' contributions}

KSJ proposed the solution, carried out the analyses and drafted the manuscript. KD independently deduced the solution for the stillbirth crossover phenomenon. All authors contributed to revising the manuscript for intellectual content. All authors read and approved the final version.

\section{Acknowledgments}

We are grateful to the National Center for Health Statistics for providing us with access to data from the United States. Dr. Joseph is supported by a Clinical Research Scholarship from the Dalhousie University Faculty of Medicine and a Peter Lougheed/CIHR New Investigator award from the Canadian Institutes of Health Research. Dr. Ananth is partially supported by a grant (ROI) from the National Institute of Child Health and Human Development, National Institutes of Health. Dr. Platt and Dr. Kramer are career scientists of the Canadian Institutes of Health Research.

\section{References}

I. Yerushalmy J: The relationship of parents' cigarette smoking to outcome of pregnancy - implications as to the problem of inferring causation from observed associations. Am J Epidemiol 197I, 93:443-56.

2. Wilcox AJ, Russell IT: Why small black infant have lower mortality than small white infants: the case for population-specific standards for birth weight. J Pediatr 1990, I I 6:7-10.

3. Hertz-Picciotto I, Din-Dzietham R: Comparisons of infant mortality using a percentile- based method of standardization for birthweight or gestational age. Epidemiol 1998, 9:61-7.

4. Meyer MB, Comstock GW: Maternal cigarette smoking and perinatal mortality. Am J Epidemiol 1972, 96: I- I0

5. Lie RT: Invited commentary: Intersecting perinatal mortality curves by gestational age - are appearances deceiving? $\mathrm{Am}$ ] Epidemiol 2000, 152: III7-9.

6. Wilcox AJ, Russell IT: Birthweight and perinatal mortality: III. Towards a new method of analysis. Int J Epidemiol 1986, I5:188-96

7. English PB, Eskenazi B: Reinterpreting the effects of maternal smoking on infant birthweight and perinatal mortality: a multivariate approach to birth weight standardization. Int J Epidemiol 1992, 21:1097-1105.

8. Wilcox AJ, Skjœrven R: Birth weight and perinatal mortality: the effect of gestational age. Am J Public Health 1992, 82:378-82.

9. Wilcox AJ: Birth weight and perinatal mortality: the effect of maternal smoking. Am J Epidemiol 1993, 137:1098-I I04.

10. Buekens $P$, Wilcox $A$ : Why do small twins have a lower mortality than small singletons? Am J Obstet Gynecol I993, I68:937-4I.

II. Wilcox AJ, Skjœrven R, Buekens P, Kiely J: Birth weight and perinatal mortality: A comparison of the United States and Norway. JAMA 1995, 272:709-II.

12. Cheung YB, Yip P, Karlberg J: Mortality of twins and singletons by gestational age: a varying-coefficient approach. $A m$ Epidemiol 2000, 152:1107-16.

13. Wilcox AJ: On the importance - and the unimportance - of birthweight. Int J Epidemiol 200I, 30:1233-4I.

14. Mittendorf R, Williams MA, Kennedy JL Jr, Berry RE, Herschel M, Aronson MP, Davidson KM: A hypothesis to explain paradoxical racial differences in neonatal mortality. Am J Prev Med 1993 9:327-330.

15. Platt RW, Yang H, Kramer MS, Joseph KS: Maturity, growth and infant mortality: a new approach [abstract]. Paediatric Perinat Epidemiol 2000, 14:A25.
16. Joseph KS, Liu S, Demissie K, Wen SW, Platt RW, Ananth CV, Dzakpasu S, Sauve R, Allen AC, Kramer MS, for the Fetal and Infant Health Study Group of the Canadian Perinatal Surveillance System: A parsimonious explanation for intersecting perinatal mortality curves: understanding the effects of plurality and parity. $B M C$ Pregnancy Childbirth 2003, 3:3.

17. Joseph KS: Incidence-based measures of birth, growth-restriction and death can free perinatal epidemiology from erroneous concepts of risk. J Clin Epidemiol 2004 in press.

18. Taffel S, Johnson D, Heuse R: A method of imputing length of gestation on birth certificates. Vital Health Stat 2 1982, 93: I- II.

19. MacDorman MF, Atkinson JO: Infant mortality statistics from the linked birth/infant death data set - $1991-95$ period data. Monthly Vital Statistics Report Volume 46. Issue Suppl 2 Hyattsville, MD: National Center for Health Statistics; 1998.

20. Joseph KS, Allen AC, Lutfi S, Murphy-Kaulbeck L, Vincer MJ, Wood E: Does the risk of cerebral palsy increase or decrease with increasing gestational age? BMC Pregnancy Childbirth 2003, 3:8.

21. Rothman KJ, Greenland S: Modern epidemiology. Second edition. Lippincott-Raven Publishers. Philadelphia; 1998:p 287-89.

22. Alexander G, Himes J, Kaufman R, Mor J, Kogan M: A United States national reference for fetal growth. Obstet Gynecol 1996, 87:163-8.

23. Ventura SJ, Martin JA, Curtin SC, Mathews TJ: Births: Final data for 1997. National vital statistics reports Volume 47. Issue 18 Hyattsville, Maryland: National Center for Health Statistics; 1999.

24. Kramer MS: Birthweight and infant mortality: perceptions and pitfalls. Paediatr Perinat Epidemiol 1990, 4:38I-90.

25. Adams MM: The continuing challenge of preterm delivery. JAMA 1995, 272:739-40.

26. Kramer MS: Maternal nutrition, pregnancy outcome and public health policy. CMAJ 1998, 159:663-5.

27. Yudkin PL, Wood L, Redman CWG: Risk of unexplained stillbirth at different gestational ages. Lancet 1987, I: I 192-4.

28. Ferguson R, Myers SA: Population study of the risk of fetal death and its relationship to birth weight, gestational age, and race. Am J Perinatol 1994, I I:267-72.

29. Hilder L, Costeloe K, Thilaganathan B: Prolonged pregnancy: evaluating gestation- specific risks of fetal and infant mortality. Br J Obstet Gynaecol 1998, 105:169-73.

30. Liu S, Joseph KS, Wen SW, Kramer MS, Marcoux S, Ohlsson A, Sauve $R$ : Changing patterns of fetal and infant death due to congenital anomalies in Canada. Am J Med Genetics 200I, 104:7-13.

31. Joseph KS, Marcoux S, Ohlsson A, Liu S, Allen AC, Kramer MS, Wen SW: Changes in stillbirth and infant mortality associated with increases in preterm birth among twins. Pediatrics 200I, 108: 1055-6I.

32. Kramer MS, Liu S, Luo Z, Yuan H, Platt RW, Joseph KS: Analysis of perinatal mortality and its components: time for a change? Am J Epidemiol 2002, I 56:493-7.

33. Joseph KS, Demissie K, Kramer MS: Trends in obstetric intervention, stillbirth and preterm birth. Semin Perinatol 2002, 26:250-9.

34. Sairam S, Costeloe K. Thilaganathan B: Prospective risk of stillbirth in multiple-gestation pregnancies: a population-based analysis. Obstet Gynecol 2002, 100:638-41.

35. Liu S, Joseph KS, Wen SW: Trends in fetal and infant deaths due to congenital anamalies. Semin Perinatol 2002, 26:268-276.

36. Smith GC, Pell JP, Dobbie R: Caesarean section and risk of unexplained stillbirth in subsequent pregnancy. Lancet 2003, 362:779-84

37. Kahn B, Lumey LH, Zybert PA, Lorenz JM, Cleary-Goldman J, D'Alton ME, Robinson JN: Prospective risk of fetal death in singleton, twin, and triplet gestations: implications for practice. Obstet Gynecol 2003, 102:685-92.

38. Caughey $A B$, Musci $T$ J: Complications of term pregnancies beyond 37 weeks of gestation. Obstet Gynecol 2004, 1 03:57-62.

39. Yawn BP, Wollan P, McKeon K, Field CS: Temporal changes in rates and reasons for medical induction of term labor, 1980 1996. Am J Obstet Gynecol 200 I, I 84:6 II-9.

40. Rayburn WF, Zhang J: Rising rates of labor induction: present concerns and future strategies. Obstet Gynecol 2002, 100:164-7.

4I. Zhang Y Yancey MK, Henderson CE. U.S. national trends in labor induction, 1989-1998. I Reprod Med 2002, 47: I 20-4

42. Joseph KS, Wilkins R, Dodds L, Allen VM, Ohlsson A, Marcoux S, Liston R: Gestational age-specific fetal growth-restriction and perinatal mortality among males and females and among 
whites and blacks (Abstract B44). Annual meeting of the Society for Pediatric and Perinatal Epidemiologic Research. Atlanta 2003 [http:// www.sper.org/2003posterB.pdf].

43. Platt RW, Joseph KS, Ananth CV, Grondines J, Abrahamowicz M, Kramer MS: A proportional hazards model with time-dependent covariates and time-varying effects for analysis of fetal and infant death. Am J Epidemiol 2004 in press.

44. Scott DT, Tyson JE: Follow up of infants discharged from newborn intensive care. In: Oski's pediatrics - principles and practice Edited by: McMillan JA, DeAngelis CD, Feigin RD, Warshaw JB. Lippincott Williams \& Wilkins. New York; 1999:209-14.

45. Dietz PM, Adams MM, Kendrick JS, Mathis MP, the PRAMS Working Group: Completeness of ascertainment of prenatal smoking using birth certificates and confidential questionnaires: variations by maternal attributes and infant birth weight. $\mathrm{Am} J$ Epidemiol 1998, 148: 1048-54.

\section{Pre-publication history}

The pre-publication history for this paper can be accessed here:

http://www.biomedcentral.com/1471-2393/4/7/prepub

Publish with Bio Med Central and every scientist can read your work free of charge

"BioMed Central will be the most significant development for disseminating the results of biomedical research in our lifetime. "

Sir Paul Nurse, Cancer Research UK

Your research papers will be:

- available free of charge to the entire biomedical community

- peer reviewed and published immediately upon acceptance

- cited in PubMed and archived on PubMed Central

- yours - you keep the copyright

Submit your manuscript here:

http://www.biomedcentral.com/info/publishing_adv.asp
BioMedcentral 